\title{
A taxonomy of shape-changing behavior for 4D printed parts using shape-memory polymers
}

\author{
Seokwoo $\mathrm{Nam}^{1}$ (D) Eujin Pei ${ }^{1}$
}

Received: 18 August 2018 / Accepted: 18 February 2019 / Published online: 28 March 2019

(c) The Author(s) 2019

\begin{abstract}
4D printing (4DP) combines the use of additive manufacturing (AM) to produce freeform components with stimuli-responsive materials, so that the printed parts can transform over a calculated duration of time. This paper provides a collective review of the transformational behavior of $4 \mathrm{D}$ printed parts that can be achieved using shape-memory polymers (SMPs). Using the process of 4DP, flat-packed structures can be printed and activated by external stimuli to transform into fully deployed functional structures. The paper provides designers and engineers with an understanding of the possibilities of shape-changing behaviors that can be realized using 4DP, where examples of existing work are referenced. From this knowledge, designers and engineers are able to implement suitable design strategies using computer-aided-design (CAD) to better control the shape-change behavior. We summarize our findings using a taxonomy of shape-changing behaviors that can be categorized according to basic, complex, and combined behaviors.
\end{abstract}

Keywords $4 \mathrm{D}$ printing $\cdot$ Shape-memory polymers $\cdot$ Stimuli $\cdot$ Shape change $\cdot$ Design for additive manufacturing

\section{Introduction}

Additive manufacturing ( $\mathrm{AM}$ ) has been recognized as a disruptive manufacturing process with considerable progress in the use of novel materials and machines. In recent years, 4D printing (4DP) has attracted attention as a new technology in which components can morph, change their shape, assemble themselves, or transform into a new form after time or when arbitrary environmental conditions are satisfied [5, 48]. With the development of 4DP technologies, widespread applications are expected to increase such as in the field of medical, construction, and robotics. The backbone of $4 \mathrm{D}$ printing requires the use of smart materials, including shape-memory alloys (SMAs) and shape-memory polymers (SMPs), although organic materials such as wood and paper can be used as bio-responsive materials. Statistics show that the

Seokwoo Nam

Seokwoo.Nam@brunel.ac.uk

Eujin Pei

eujin.pei@brunel.ac.uk

1 Department of Design, Institute of Materials and Manufacturing, Brunel University London, Michael Sterling Building MCST156, Kingston Lane, Uxbridge UB8 3PH, UK market size of shape-memory polymers (SMPs) is expected to grow from US $\$ 1$ billion in 2021 to US $\$ 3.4$ billion in 2025 [38]. For this paper, we shall focus on SMPs as they are more advantageous when compared to SMAs, because the current technologies have enabled them to be lighter, more cost-effective and have a higher recoverable strain than SMAs [16]. It is also expected that the widespread adoption of using SMPs is more achievable when compared to SMAs which will typically involve more complex processes [22]. This paper provides a comprehensive review of the transformation of 4D printed parts that can be achieved using shape-memory polymers (SMPs). For example, using 4DP, different forms of structures can be printed and activated in a timely and controlled way by external stimuli to transform into fully deployed functional assemblies. In the design stage, designers and engineers need to recognize and understand the various shape-change effects of 4DP parts. This paper has four sections. The next section discusses the state-of-art of AM and 4DP. Section 3 compares SMPs and SMAs, and discusses how the environmental stimuli can have an effect on SMPs. Finally, Sect. 4 compiles a list of transformation changes that can be achieved using 4DP and the authors propose a classification system. 


\section{4D printing (4DP)}

\subsection{An overview of additive manufacturing}

Additive manufacturing (AM) is a process of building components in layers directly from 3D CAD data, without the need for complex and costly tools and with minimal material. It is a process of joining materials to make parts from 3D model data, usually layer upon layer, as opposed to subtractive manufacturing and formative manufacturing methodologies [19]. Additive manufacturing (AM) uses methods such as material extrusion, material jetting, binder jetting, and sheet lamination to build solid threedimensional structures through the controlled deposition of materials one layer after another. Most AM processes today enable the production of mechanically stable parts that are rigid and static to achieve its intended form. Consequentially, most of these parts are not designed to actuate or transform. Moving parts such as hinges or actuators involve assembling multiple parts together after being produced [14]. The post-processing of putting together separate parts requires specific tolerances and also takes time to assemble. One answer to this is to use materials that can morph in a controlled manner over time when it is exposed to external stimuli.

\subsection{DP technology}

4D printing technology capitalizes on the rapid development of smart materials such as SMAs and SMPs with freeform digital manufacturing processes. An AM produced, self-changing structure that responses to an external trigger such as heat, light, electricity, or other stimuli is called a $4 \mathrm{D}$ printed part $[39,40]$. 4D printing uses time as the fourth dimension, in the sense that the object can change over a duration, dependent on environmental stimuli [37]. The biggest advantage of utilizing 4DP is size reduction due to the computational folding that can be achieved. In AM parts, most machine build sizes have to accommodate the surface area and volume of the part. However, 4D printing does not have such constraints because large parts can be "folded" or "compressed" in sections and printed to fit into the constraints of the machine bed. Farhang et al. [10] highlighted that the fundamental elements of 4DP include the AM process, the stimuli, the stimuli-responsive material, interaction mechanism, and mathematical modeling. Figure 1 describes that the AM process is necessary for the production of freeform parts; and the stimuli, in turn, trigger the stimuli-responsive material into its new form. The interaction mechanism is the programming process in which

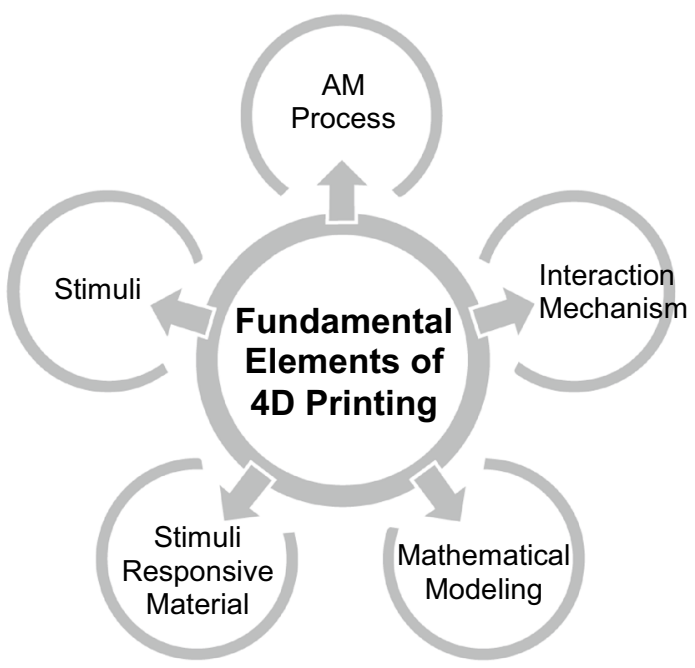

Fig. 1 Fundamental elements of 4DP [10]

the material is deformed into a temporary shape. Finally, the mathematical modeling process defines the material distribution and its structure needed to achieve the desired change in its shape [10].

The mathematical modeling process is intrinsically linked to the overall design of the part which is in turn linked to the computer-aided-design model. For example, the shapeshifting behavior can be enabled by incorporating targeted smart hinges at precise locations within the structure [10, $14,36,50]$. The hinges are made from smart materials and all the other parts constitute non-reactive materials (Fig. 2).

Instead of stacking uniform layers to exhibit different dimensional changes that respond to the stimuli, the shapememory material could be arranged by controlling the amount, location, and pattern, so that different effects such as swelling ratios could be generated upon activation when exposed to stimuli. Figure 3 shows the results of the material when different swelling ratios are achieved [23, 49, 55].

\subsection{Current application of 4D printing}

4D printing is still in its early stages of development. Below are the current examples of emerging 4D printing applications that demonstrate the potential to reshape new product development in several ways. Figure 4 is a 4D printed smart valve. The team at the ARC Centre of Excellence for electromaterials' science described that the use of shape-memory materials can be transformed from one form to another and could be applied for use in medical soft robotics. This combination of technology and materials was used to create a valve that works in response to the temperature of the water surrounding the valve.

Figure 5 illustrates that MIT's Tangible Media Group has developed a novel "pasta" that can respond in a 

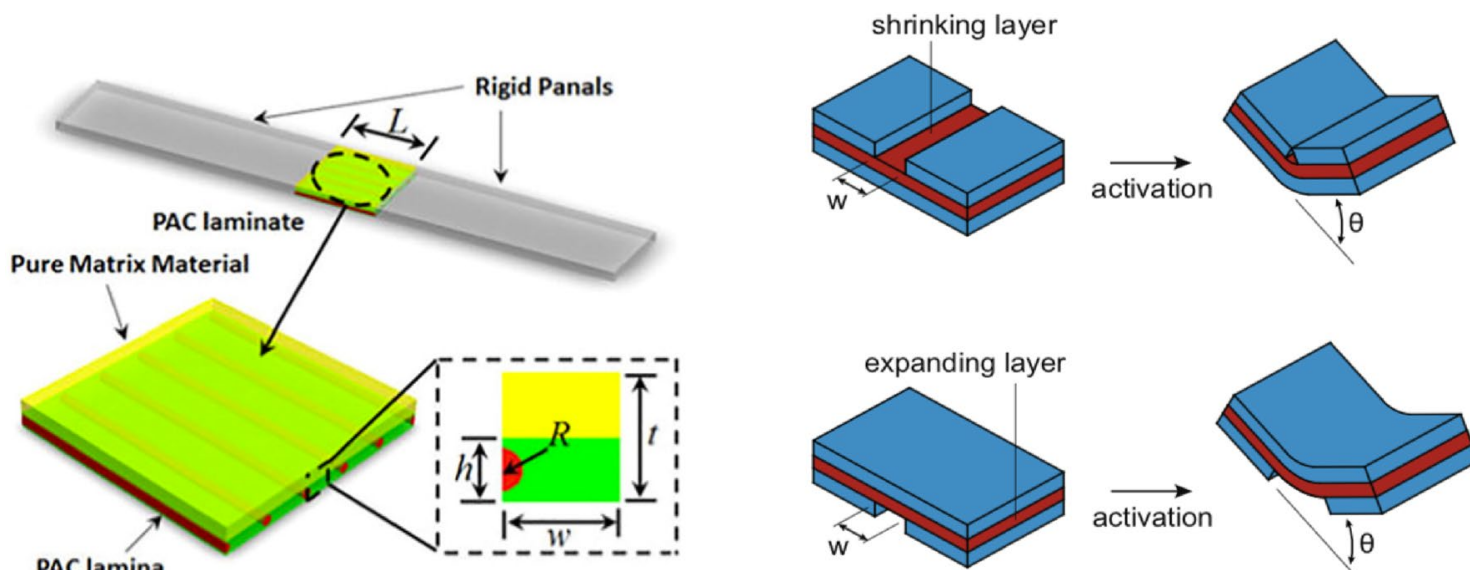

PAC lamina
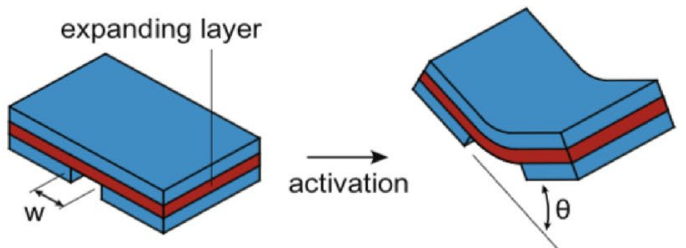

Fig. 2 Structures with a smart hinge [14, 36, 50]

a
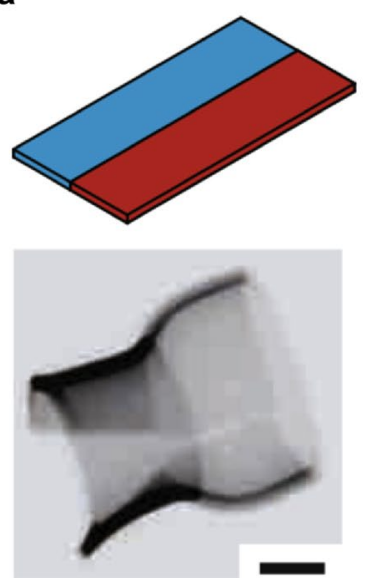

b
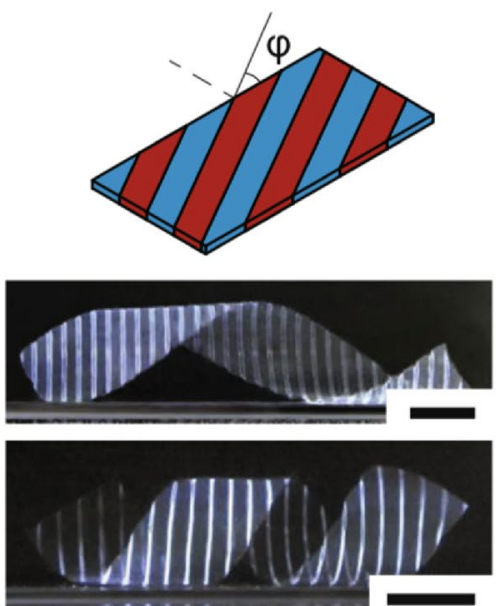
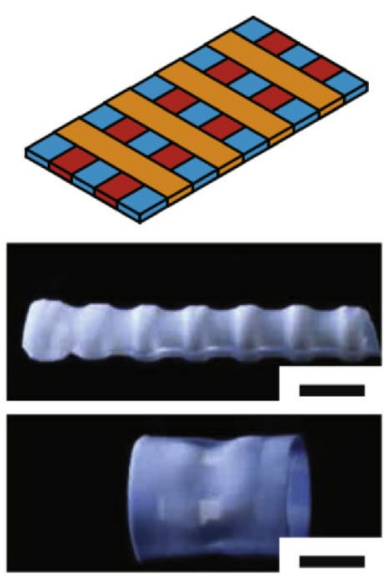

Fig. 3 Multiple material tessellations resulting in different shape-shifting materials [23, 49, 55]
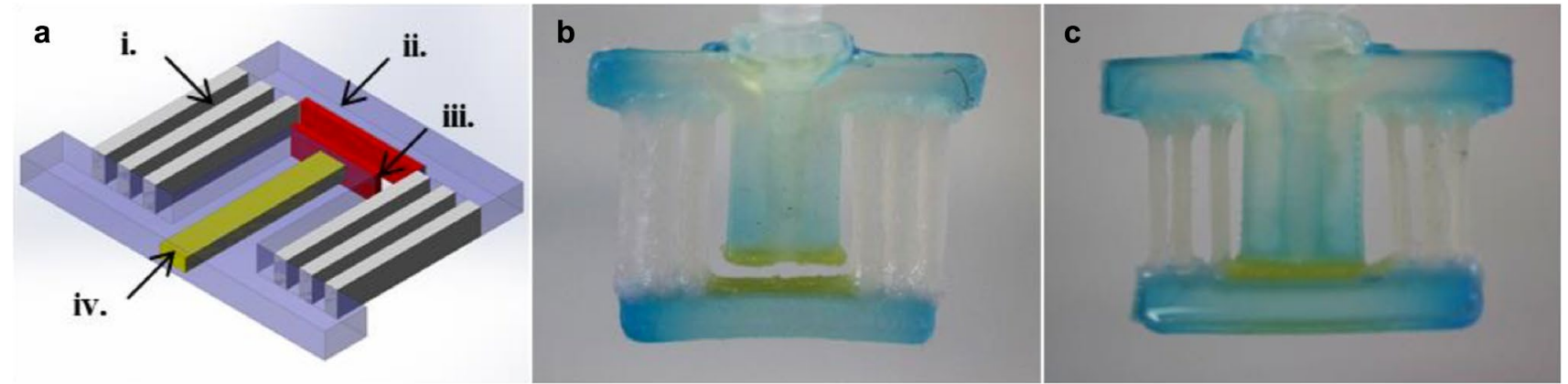

Fig. 4 A smart valve is created by $4 \mathrm{D}$ printing [3]

variety of ways that fold when in contact with heat and water. The printed Pasta is flat, and when boiled, it can achieve different shape deformations such as bending, folding, and rolling. To achieve this effect, Wang et al. [53] 3D printed a piece of edible cellulose over the top layer of the gelatin. 

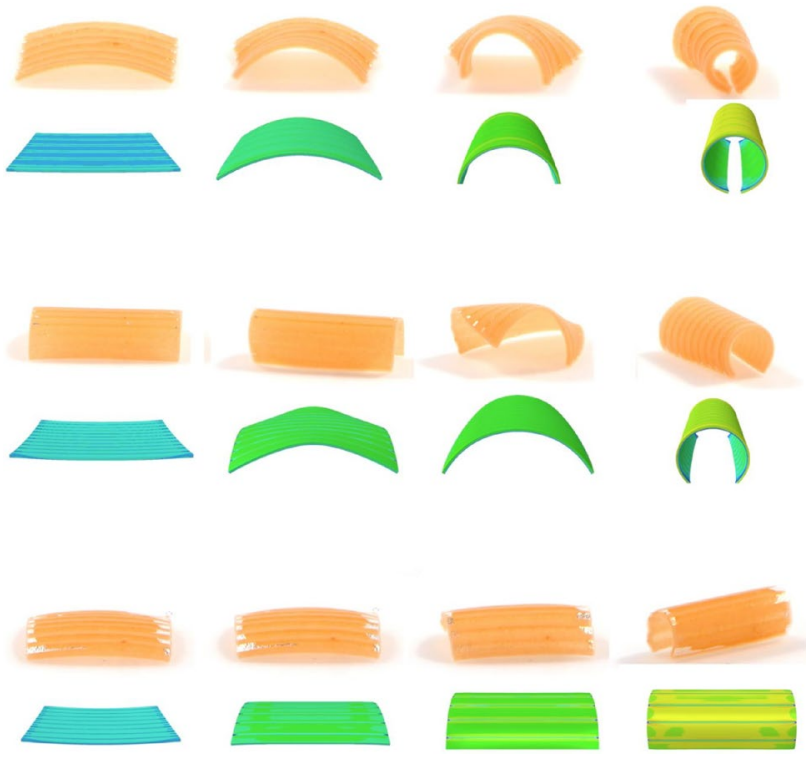

Fig. 5 Shape-shifting pasta [53]

Fig. 6 Stimuli-responsive materials [47]
According to a market-research report by Frost and Sullivan [12], 4D technology and equipment are expected to grow rapidly in the medical, aerospace, defense, and automotive industries. $4 \mathrm{D}$ printing can produce a variety of products to support components for use in automotive parts to human organs. Benefits of 4D printing include improved functionality of mechanical products, new uses of adaptive materials, additional manufacturing efficiency, and reduced manufacturing costs and carbon emissions. In addition, according to the Market research future [34], 4D printing technology is expected to be widely used in aerospace and defense, healthcare, automotive, construction, clothing, utilities, and others.

\section{Overview of shape-memory polymers (SMPs)}

\subsection{Differences between SMAs and SMPs}

Smart materials have a dual-shape capability that can transform from one defined shape to another when stimulated. These stimuli-responsive materials can be classified

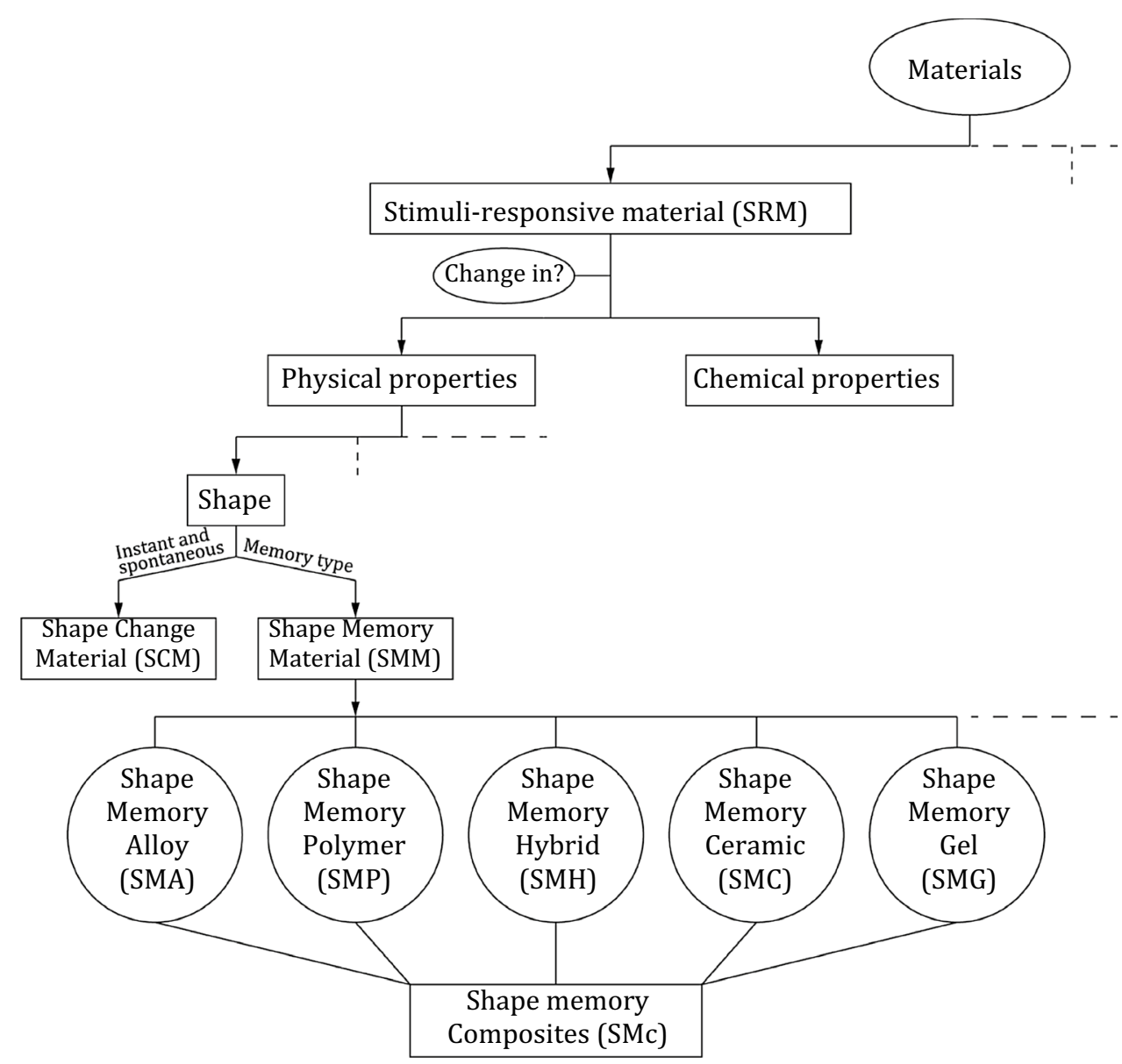


into several sub-categories, as shown in Fig. 6. However, shape-memory alloys (SMAs) and shape-memory polymers (SMPs) are the most commonly used materials for 4D printed parts [22]. The idea of using stimuli-responsive materials was initially based on thermally actuated shapes and today's applications range from heat shrinkable tubes to smart medical devices. The application of shape-memory materials requires a combination of suitable materials and accurate programming. A temporary shape is achieved through a deformation process. In 4D printing, shape-memory polymers (SMPs) are commonly used as compared to SMAs. SMPs have a wider range of glass transition temperatures from -70 to $100{ }^{\circ} \mathrm{C}$. SMPs also have the potential to achieve configuration recovery properties of up to $400 \%$ of the plastic strain, while the recovery properties of SMAs are approximately $7-8 \%$. SMAs are considered to be disadvantageous due to complex production, high costs, toxicity, and limited recovery (Table 1). Therefore, SMPs and hydrogels are preferred over the use of shape-memory alloys (SMAs) [9].

\subsection{Characteristics of SMPs}

Although SMPs were developed over 30 years ago, the past few years have seen SMP research progressing significantly in which material scientists have developed from singleshape to multi-shape properties, and to design completely reversible transformative capabilities during this short span of time. SMPs possess at least two phases-a stable phase which stabilizes the polymer and this is used to recover the original shape; as well as a second (or temporary) phase. The deformation of the first phase is the force required to recover the original shape, and this is achieved through the interpenetrating networks, chemical crosslinks, or crystalline phases of the material [35]. The second-phase momentarily fixes the temporary shape by the glass transition $\left(T_{\mathrm{g}}\right)$ or crystallization state between the different liquid crystalline phases, through covalent or non-covalent bonds such as Diels-Alder reactions, which is a thermo-reversible reaction. Other stimuli-responsive methods such as switching by redox reactions can also be applied. The mechanism of
SMPs is commonly achieved through thermal transitions, thermo-responsiveness, and chemo-responsiveness. The thermal transition of SMPs is due to molecular switches/ net points that are physical and chemical crosslinks. Phasesegregated morphology and formation are the foundational mechanism behind the state of material change [25]. In thermosets, the network chains between net points consist of switch segments of chemical crosslinks. The shape-memory switch is achieved through a thermal transition of the polymer segments. Thermosets display less creep and, therefore, show a less irreversible change during transformation when compared to thermoplastics. They also display better shape, mechanical, and thermal memory than thermoplastics [26]. For thermo-responsive SMPs, a dual-component system is used in polymers that are excited by heat. The matrix remains elastic throughout and the fibers reversibly change in material stiffness $[32,41]$. Thermo-responsive SMPs use the Glass Transition or the melting point as the threshold temperature. The SMP has two stages, in which the first is the deformation to a temporary shape (or the programming stage); and the second stage is the recovery phase [18]. Finally, for chemo-responsive SMPs, immersion in a chemical stimulates the plasticizing effect of the polymer [43]. This effect often reduces the glass transition temperature $\left(T_{\mathrm{g}}\right)$ of the material and there is a need to heat the material over the $T_{\mathrm{g}}$. There are alternatives for shape recovery due to this chemical responsiveness. It can be triggered by the ionic strength, the $\mathrm{pH}$ value, or the concentration of the agent [29]. Currently, thermo-responsive SMPs are most applicable for 4DP parts, followed by chemo-responsive SMPs particularly using hydration. The methods that can be used to print thermo-responsive SMPs include material extrusion, material jetting, and stereolithography. As for chemo-responsive SMPs, usually hydrogels are used and bio-extrusion is the most common method of fabrication [25].

\subsection{Stimuli and the shape-memory effect (SME)}

Materials that can respond and change its configuration according to the environmental conditions are often selected for use in 4DP. Global deformation of the material can be
Table 1 Comparison between SMPs and SMAs [27]

\begin{tabular}{lll}
\hline Property & Shape-memory polymers & Shape-memory alloys \\
\hline Density $\left(\mathrm{g} / \mathrm{cm}^{3}\right)$ & $0.9-1.2$ & $6-8$ \\
Extent of deformation & $\mathrm{Up} \mathrm{to} 800 \%$ & $<8 \%$ \\
Required stress for deformation $(\mathrm{MPa})$ & $1-3$ & $50-200$ \\
Stress generated upon recovery $(\mathrm{MPa})$ & $1-3$ & $150-300$ \\
Transition temperature $\left({ }^{\circ} \mathrm{C}\right)$ & -10 to 100 & -10 to 100 \\
Recovery speed & $1 \mathrm{~s}$ to min & $<1 \mathrm{~s}$ \\
Processing condition & $<200^{\circ} \mathrm{C} ;$ low pressure & $>1000{ }^{\circ} \mathrm{C} ;$ high pressure \\
Cost & $<\$ 10 / \mathrm{lb}(£ 7.5 / \mathrm{lb})$ & $\mathrm{Appx} . \$ 250 / \mathrm{lb}(£ 189 / \mathrm{lb})$ \\
\hline
\end{tabular}


achieved when exposed to external changes such as water and temperature that are commonly used as the activation stimuli. When combined with the other less-exploited triggers such as magnetism, light, and $\mathrm{pH}$, they open up new avenues to design smarter devices [2]. Thermal-responsive SMPs, through heating from a source such as heated gas or water, can also trigger the SME. Other methods for SMP actuation that have shown potential for application include light and electricity sources. SMPs are characterized by their ability to recover their original shape from a temporary form that they take on. They remain in the temporary shape until an external stimulant is used and then it reverts back to its original shape. This process is known as the shape-memory effect (SME). The geometrical design and responsiveness of the material influences the transition speed of the material from one form to another. The amount of shapes that can be retained in the memory of the material depends on its network elasticity. The strain recovery rate $\left(R_{\mathrm{r}}\right)$ and the strain fixity rate $\left(R_{\mathrm{f}}\right)$ determine the "intensity" of the SME. The strain recovery rate $\left(R_{\mathrm{r}}\right)$ is the ability of the material to memorize its permanent shape; and the strain fixity rate $\left(R_{\mathrm{f}}\right)$ refers to the ability of the switching segments within the mechanical deformation. Materials can be either reversible or irreversible. Reversible materials usually have two-way memories, since they have two permanent stages, although most existing SMPs are almost limited to one-way memory, needing reprogramming after each recovery. Two-way SMPs have an SME that can change back and forth from a temporary shape back to a permanent shape. Smart or stimulus-responsive material: stimulus-responsive material is one of the most critical components of $4 \mathrm{D}$ printing. Stimulus-responsive materials can be classified into several sub-categories, as shown in Fig. 6 [47].

\section{Shape change through 4D printing}

\subsection{Basic, complex, and combination shape-changing behaviors}

As an emerging, future-ready technology, 4D printing has added an extra dimension to the progress of additive manufacturing where structures can morph after being exposed to triggers such as light and heat. The manufactured constituent is capable of small or radical changes that can result in totally new structures. We classify shape-change behaviors into three categories-basic shape change, complex shape change, and a combination of shape change. Basic shape changing involves only a process of single deformation. The main characteristic is that it is a single-step process that produces a wholly uniform effect. Basic shape-changing behaviors include bending, rolling, twisting, helixing, buckling, curving, topographical change, expansion, and contraction.
Basic shapes can be programmed to undergo a specified sequence of deformations over time to subsequently achieve complex shapes, sometimes also known as "sequential" shape-shifting [31]. Complex shape-changing behaviors consist of multiple deformations which can be derived from extending an earlier form of a basic shape change or as a completely multi-faceted form. For example, multiple folding, multiple bending, multiple rolling, multiple twisting, multiple helixing, multiple buckling, multiple topographical changes, and curvature changes are extended behaviors of the basic shape change. Other complicated shape-change behaviors include waving and curling. Finally, a combination type of shape changing is an amalgamation of different types of shape-changing behaviors in which two or more constituent behaviors can be programmed to occur in the component either simultaneously or in a carefully timed sequence. In terms of mathematical analysis, all shape deformation is a resultant of different stress along the plane. It is influenced by different strains, gradients, and shapes. Taking a step further, Table 2 summarizes the differences of shape-changing behaviors through a mechanical analysis lens.

\subsection{Basic shape-changing behaviors}

Basic shape-changing behavior results in a single deformation and the transformation occurs as a one-step process. This includes folding, bending, rolling, twisting, helixing, buckling, curving, topographical change, expansion, and contraction.

\subsubsection{Folding}

A fold is essentially a deformation in which the in-surface distance between the sheet's two distinct points is kept without having to self-intersect [8]. A fold is a sharp curvature caused by deformation along a crease. Folding is a localized deformation of the material which emphasizes on a narrow hinge area using sharp angles [24, 44]. Tibbits [51] produced a 4DP structure which could fold itself into a precisely truncated Octahedron. The component was printed using material jetting technology and water was used as the stimuli (Fig. 7).

\subsubsection{Bending}

Bending is the distributed deformation of a material along the deflected area that creates the curvature [24]. Wu et al. [54] produced such an actuation behavior in which two segments are linked in the middle and the orientation of the fiber remains parallel to the direction of the bending force. Figure 8 illustrates the bending behaviorbehavior, and if an array of the segments are arranged by altering the materials and position of fibers, it would also be possible to achieve 
Table 2 Mechanical analysis of each shape deformation

\begin{tabular}{|c|c|c|}
\hline \multicolumn{2}{|c|}{ Shape changing behaviour } & \multirow{2}{*}{$\begin{array}{l}\text { Mechanical analysis } \\
\text { Folding deformation is caused by a stress } \\
\text { mismatch between rigid and active materials, } \\
\text { which is possible with various swelling ratios } \\
\text { [10] }\end{array}$} \\
\hline & $\begin{array}{l}\text { Folding } \\
\text { Raviv et al. [14] } \\
\text { Tibbits [54] } \\
\text { lonov [20] }\end{array}$ & \\
\hline & $\begin{array}{l}\text { Bending } \\
\text { Gladman et al. [15] } \\
\text { Wu et al. [54]. } \\
\text { Zhang et al. [57] }\end{array}$ & $\begin{array}{l}\text { Bending deformation is the } \\
\text { swelling/shrinkage mismatch between both } \\
\text { layers in response to activation stimuli, while } \\
\text { sustaining the same strain at the interface } \\
\text { between both layers, could result in different } \\
\text { types of deformation [6] }\end{array}$ \\
\hline & $\begin{array}{l}\text { Rolling } \\
\text { Ge et al. [13] } \\
\text { Gladman et al. [15] }\end{array}$ & $\begin{array}{l}\text { Rolling deformation is a normalized curvature } \\
\text { that varies depending on both the expansion } \\
\text { mismatch and the thickness, which is a } \\
\text { nonlinear relationship between the rolling } \\
\text { radius of one hand and the ratio of expansion } \\
\text { and the sample thickness [4] }\end{array}$ \\
\hline & $\begin{array}{l}\text { Twisting } \\
\text { Ge et al. [13] } \\
\text { Wang et al. [53] } \\
\text { Zhang et al. [57] }\end{array}$ & $\begin{array}{l}\text { Twisting deformation printed the fibers with } \\
\text { certain angles to induce twisting, and by } \\
\text { adjusting the print angles of active fibers, the } \\
\text { final twist angle would be changed [57] }\end{array}$ \\
\hline & $\begin{array}{l}\text { Helixing } \\
\text { Zhang et al. [57] } \\
\text { lonov [20] }\end{array}$ & $\begin{array}{l}\text { Helixing deformation is made by a uniaxial } \\
\text { expanding/shrinking active layer for a } \\
\text { nonzero angle between the main straining } \\
\text { direction of the active layer and the main axis } \\
\text { of the bilayer strip [21] }\end{array}$ \\
\hline & $\begin{array}{l}\text { Buckling } \\
\text { Manen et al. [31] } \\
\text { Sharon and Efrati [46] }\end{array}$ & $\begin{array}{l}\text { Buckling deformation that compressive } \\
\text { stresses above a certain critical value will } \\
\text { induce out-of-plane buckling of the flat } \\
\text { structure [31] }\end{array}$ \\
\hline & $\begin{array}{l}\text { Curving } \\
\text { Tibbits [51] }\end{array}$ & $\begin{array}{l}\text { Based on the light intensity gradient along the } \\
\text { thickness of material, a stress gradient could } \\
\text { be created, which results in spontaneous } \\
\text { curving of the structure after release from the } \\
\text { substrate [58] }\end{array}$ \\
\hline & $\begin{array}{l}\text { Topographical change } \\
\text { Hu et al. [17] } \\
\text { Tibbits et al. [52] }\end{array}$ & $\begin{array}{l}\text { Mountain and valley features can be } \\
\text { generated from concentric circles in the } \\
\text { presence of an appropriate stimulus. Surface } \\
\text { topography is the representation of local } \\
\text { deviations of a surface from a flat plane. } \\
\text { These features usually occur under } \\
\text { compressive loading conditions [52] }\end{array}$ \\
\hline & $\begin{array}{l}\text { Expansion/contraction } \\
\text { Bakarich et al. [3] } \\
\text { Raviv et al. [42] } \\
\text { Yu et al. [56] }\end{array}$ & $\begin{array}{l}\text { "This mechanism is driven by a variety of } \\
\text { expansion ratios between active and rigid } \\
\text { materials, which consist of scalable, } \\
\text { hydrophobic active materials and rigid } \\
\text { materials [3] }\end{array}$ \\
\hline & $\begin{array}{l}\text { Waving } \\
\text { Wu et al. [54] }\end{array}$ & $\begin{array}{l}\text { Wave shape deformation could occur in } \\
\text { bilayers with comparable stiffness and layer } \\
\text { thickness through swelling/shrinkage } \\
\text { mismatch in response to activation stimuli [6] }\end{array}$ \\
\hline & $\begin{array}{l}\text { Curling } \\
\text { Tibbits et al. [52] }\end{array}$ & $\begin{array}{l}\text { Curling deformation is enabled by a stress } \\
\text { mismatch between rigid and active materials } \\
\text { from their different swelling properties [52] }\end{array}$ \\
\hline
\end{tabular}


Fig. 7 An example of a folding behavior [51]

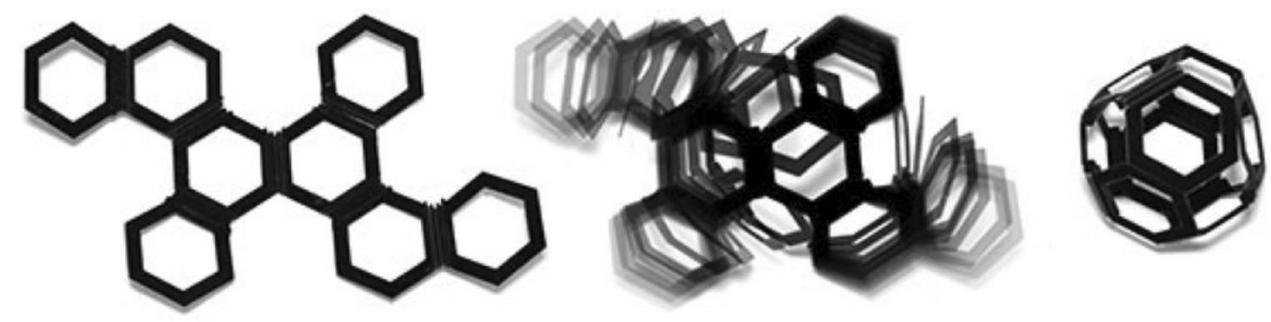

Fig. 8 An example of a bending behavior [54]

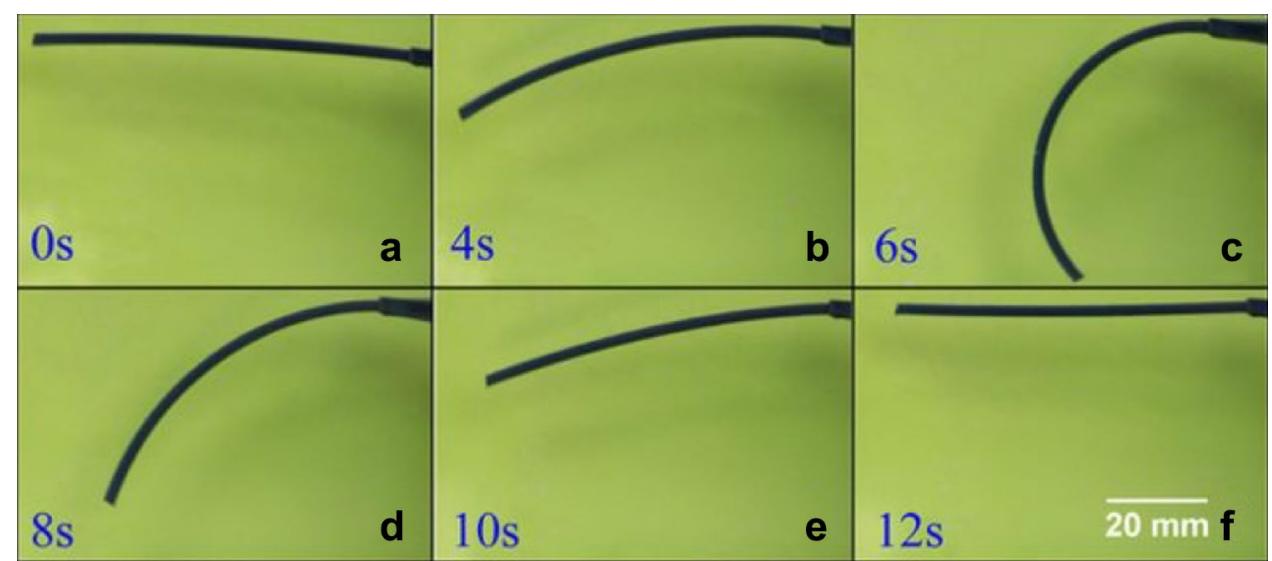

several features altogether known as a "wave" which is a complex shape. This behavior was achieved using a change in the water temperature as the stimuli.

There is a difference between folding and bending shapechange behaviors. Folding is a localized deformation that has sharp angles occurring within a narrow hinge area; while bending is a global deformation that results in a smoother curvature [44]. When a continuous force is applied to the bending effect, the shape deformation of rolling occurs. The difference between bending and rolling is the variance between the gradient after the deformation. Bending has two positive and two negative gradients, while rolling consists of various gradients (Fig. 9).

\subsubsection{Rolling}

Rolling is a behavior in which the shape moves by turning over and over on its own axis. This deformation process enables the component to maintain a constant cross section throughout the deformation process. This shape-changing behavior is usually triggered by heat in the common shapememory cycles with programming and recovery steps [10]. Figure 10 was a component produced by Ge et al. [13] that shows an example of rolling. The left image shows the strip in its original shape and the right images show the results of different fiber architectures. In general, the size of the curvature depends on the design variables such as the composite, the geometry, and its properties; the applied mechanical load; and the thermal history [13].

\subsubsection{Twisting}

The twisting action is dominated by in-plane stretching [1] It is possible to make the self-twisting strips by combining two anisotropic active layers of similar types with primary straining directions that are perpendicular to each other (Fig. 11). By increasing the twisting widths, the stretching energy increases rapidly, while the bending energy of the helix constructs is only linearly related to the width of the part. Twisting is favorable for small widths for shapechange behaviors [1]. Examples of twisting can be seen in the twisted pasta shapes produced by MIT and water was used as the stimuli (2017).

The twisting shape-change behavior is dominated by the in-plane stretching, and bending is dominated by the helixing layer. By increasing the width of its own twisted sample, the stretching energy increases very quickly, whereas the bending energy of a helixing structure is only linearly related to the sample width. Another key difference between twisting and helixing is that the axis of the twist is centered, whereas the axis of the helixing shape change has various axes [21] (Fig. 12).

\subsubsection{Helixing}

A helix is a type of smooth space deformation in which a curve occurs in a three-dimensional space. Zhang et al. [57] experimented with helical structures and various patterns of spiral like structures by forming a 2D sheet twisted into a 3D 


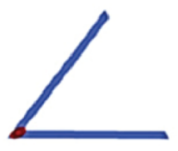

a

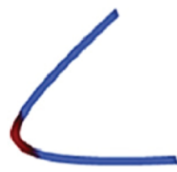

b

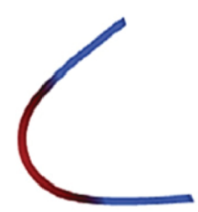

C

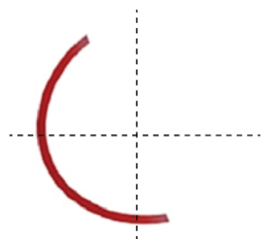

d

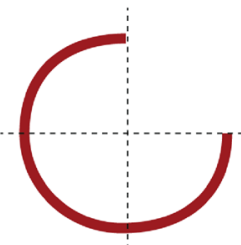

e

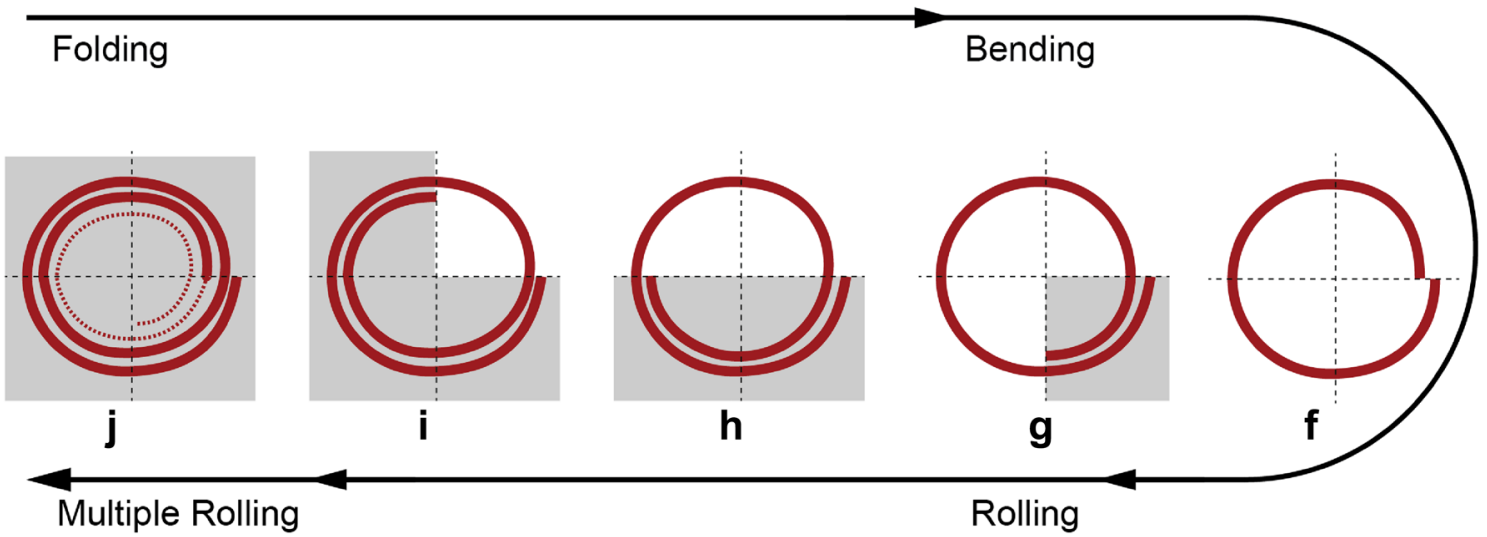

Fig. 9 The difference of folding, bending, rolling, and multiple rolling

Fig. 10 An example of a rolling behavior [13]
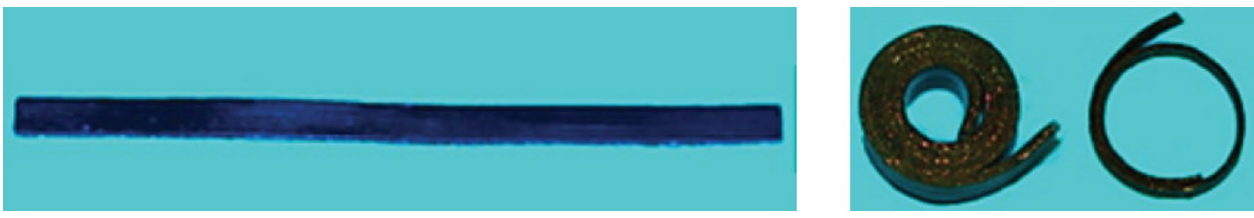

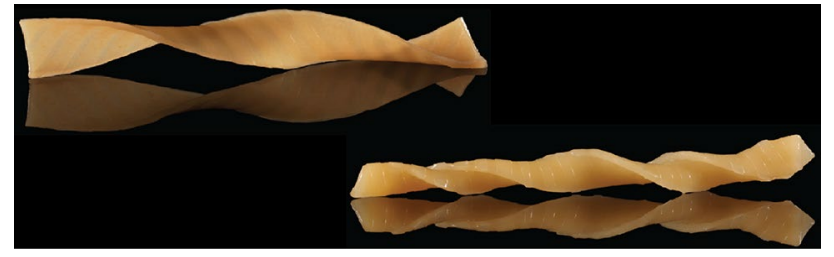

Fig. 11 An example of a twisting behavior [53]

shape. It is an example of an internal strain being produced using AM-based polymer and triggered by thermal stimuli (Fig. 13). Zhang et al. [57] used certain angles to print the fibers to induce twisting. By adjusting the active fibers' print angles, they were able to change the twisting behavior of the helix.

\subsubsection{Buckling}

Buckling is characterized by a sudden sideways failure of a structural member subjected to high compressive stress [45]. Examples of buckling behavior can be seen in the work by Manen et al. [31] in Fig. 14. This example of a buckling behavior was activated using different temperatures as the stimuli. The scale of stretching energy is usually linear with the material thickness, whereas bending behavior exhibits a cubic reliance on the thickness [31]. Material properties do not require a thickness gradient. Programming the flat layout of various active and manual elements can produce the desired compression stresses when activated. The externally generated compression force is also used in the passive material layer to induce non-planar buckles [28].

\subsubsection{Curving}

Curving is the amount by which the surface of a geometric object deviates from a flat plane. In an experiment by Tibbits [51], mountain and valley features can be generated from concentric circles in the presence of an appropriate stimuli (Fig. 15). This shape-changing behavior is enabled by a stress mismatch between rigid and active materials from their different swelling properties when in contact with water. 


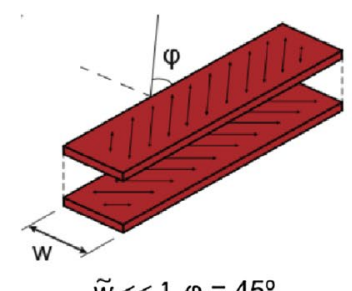

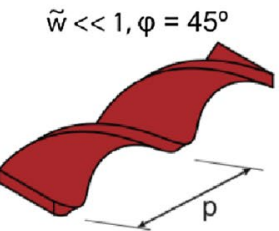

twisting
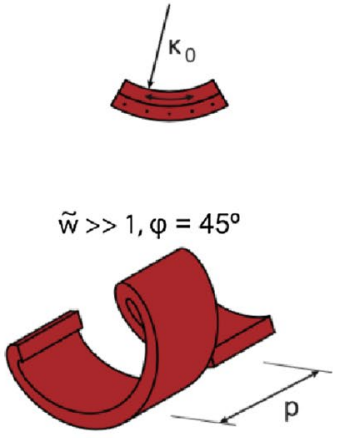

helixing
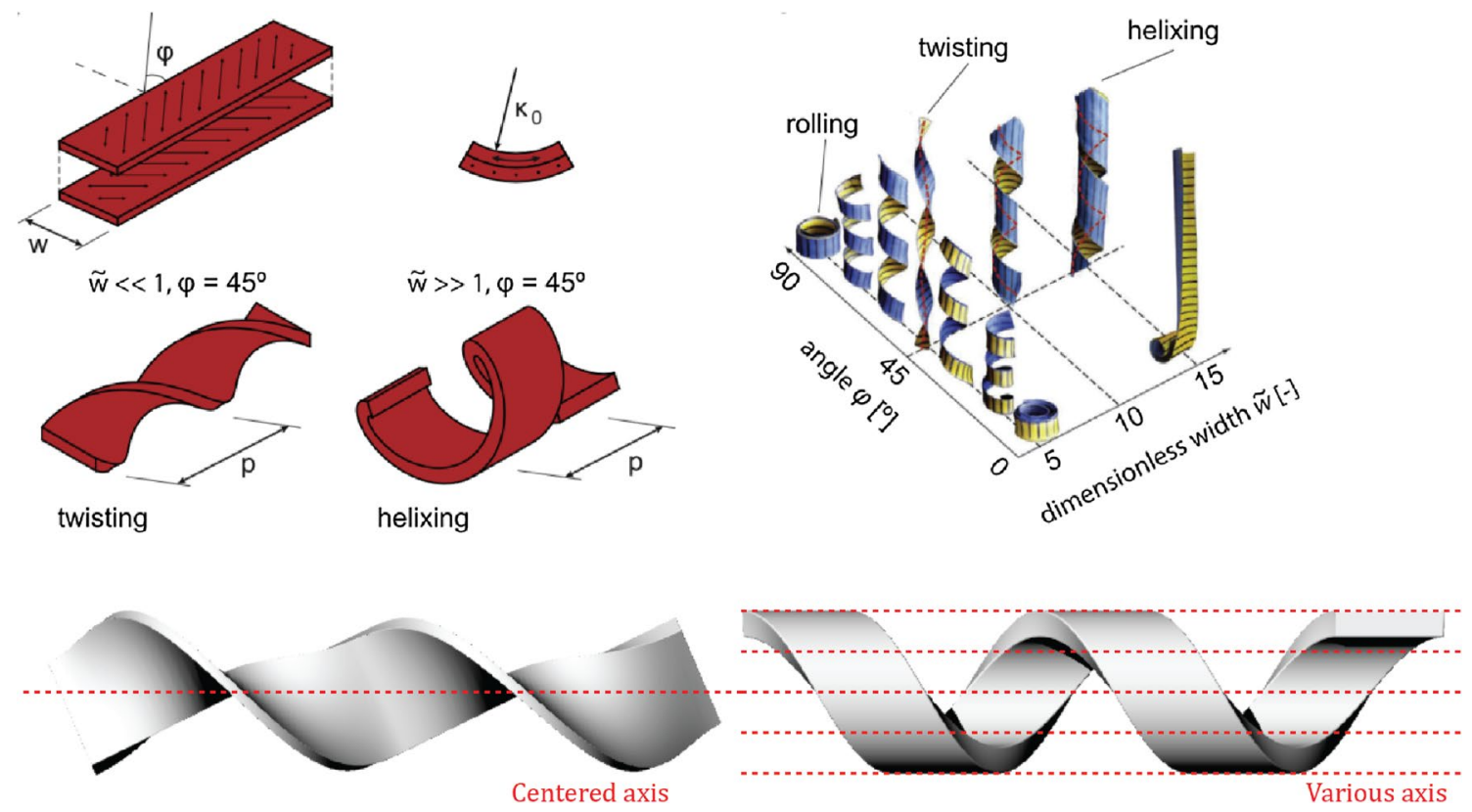

Fig. 12 The difference between twisting and helixing [11]

Fig. 13 An example of a helixing behavior [57]
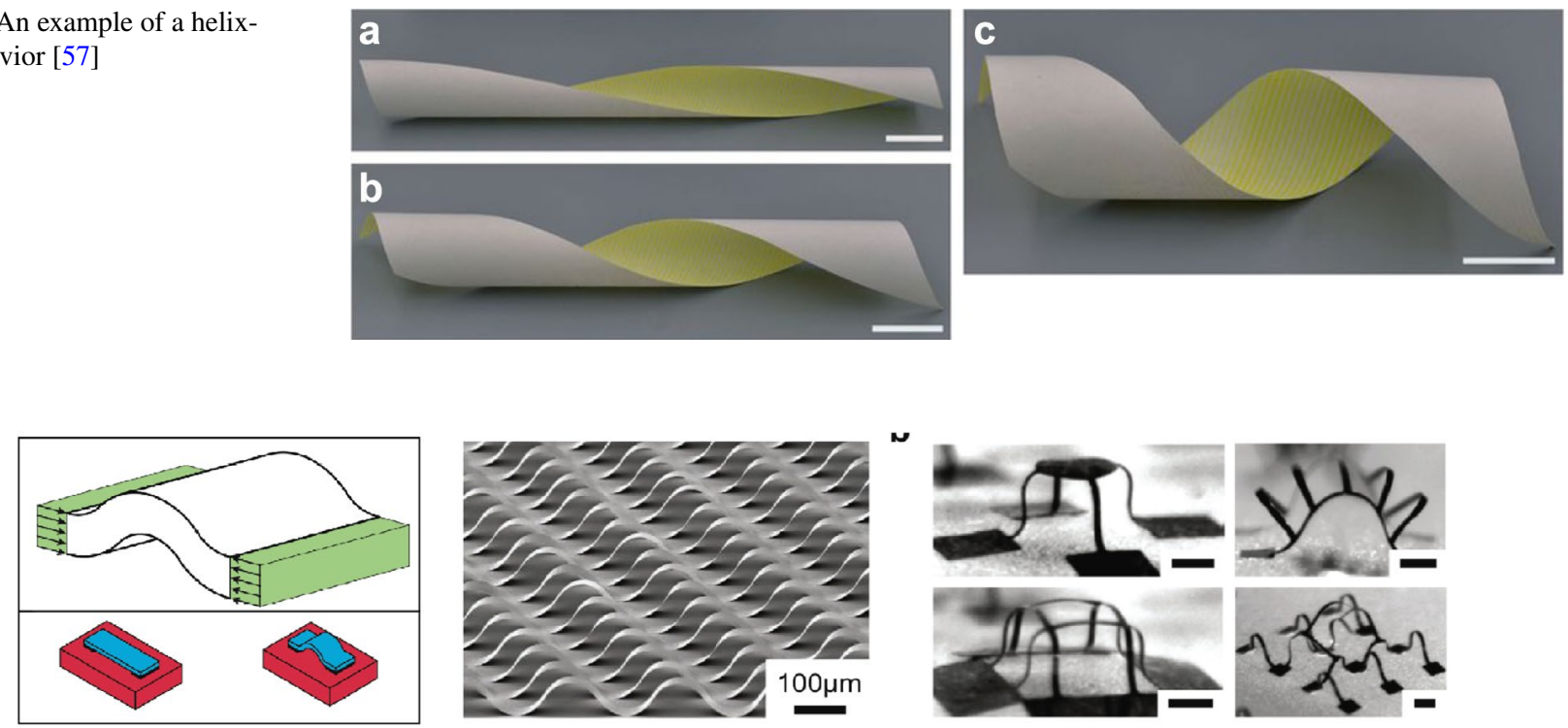

Fig. 14 An example of a buckling behavior [31]

Fig. 15 An example of a curving behavior [51]
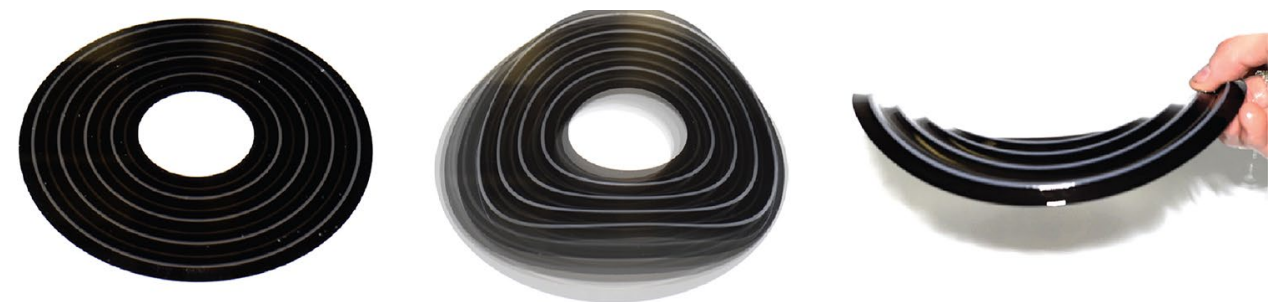

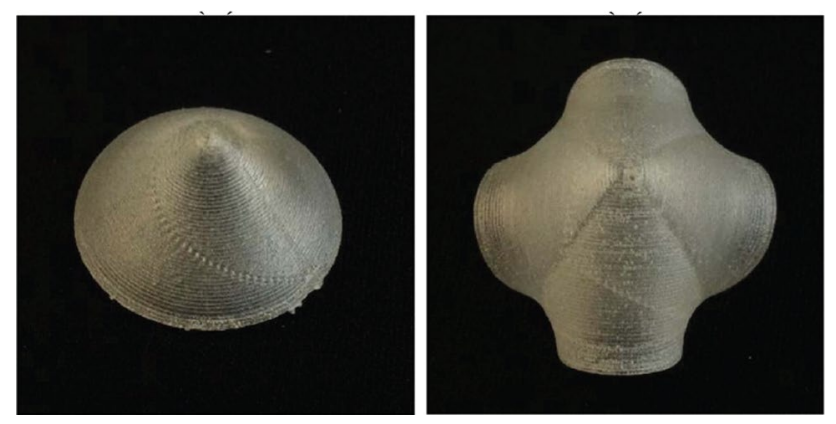

Fig. 16 An example of a topographic change behavior [17]

\subsubsection{Topographical change}

The topographical change results in a distorted shape that resembles the physical features of a ground terrain. The image on the left shows a shell with different curvatures near and further away from the central apex. While its hypotenuse is fully straight near the apex, it becomes more curved further away the apex. It can also be observed that the corners bend into the shell (Fig. 16).

\subsubsection{Expansion and contraction}

In general, materials expand when heated and contract when cooled. The shape, volume, and area of the material changes as temperatures fluctuate. Expansion and contraction shape-changing behaviors are based on a shape-memory cycle, which includes the usual programming and recovery steps for thermo-responsive SMPs. Bakarich et al. [3] demonstrated expansion and contraction behaviors of linear free swelling and shrinking of a thermo-responsive hydrogel being immersed in cold and hot water (Fig. 17).

\subsection{Complex shape-changing behaviors}

Complex shape-changing behaviors consist of multiple deformations that can be derived from extending an earlier form of a basic shape or as a completely multi-faceted form. These characteristics of multiple deformation shape-changing have one or two more steps' deformation. For example, multiple folding, multiple bending, multiple rolling, multiple twisting, multiple helixing, multiple buckling, multiple topographical changes, and curvature changes are extensions of the basic form. Other complicated structures include waving and curling.

\subsubsection{Waving}

The waving behavior results in a shape that has undulating features or a wavy up-and-down form. Wu et al. [54] produced experiments of an active "wave" shape when immersed in hot water (Fig. 18). This design of the structure requires positions of materials that are located in two segments. The wavy pattern is made up of a combination of SMPs and other laminated segments [54]. This flat tri-layer component transforms into a curved wavy shape upon heating. It is possible to achieve various wave shape-changing behaviors by altering the position and materials of each layer.

Depending on the layer thickness and the induced strain, both waving and curling can be effectively programmed. The key difference between waving and curling is the regularity of the curves after deformation. Waving has a more regular curve, while curling consists of various irregular curves (Fig. 19).

\subsubsection{Curling}

As an alternative to curved creases, we can use surface curling by creating continuous surfaces. A larger surface provides an even expansion force and usually displays the effects of curling far more visibly. Figure 20 by Tibbits et al. [52] shows an example a curling behavior.

\subsubsection{Multiple folding}

Mao et al. [33] demonstrated a sequence of self-folding operations for transforming a 2D strip into 3D shape, as shown in Fig. 21. The folding behavior was triggered by heat in multiple shape-memory cycles with programming
Fig. 17 An example of an expansion and contraction behavior [3]

Fig. 18 An example of a waving behavior [54]
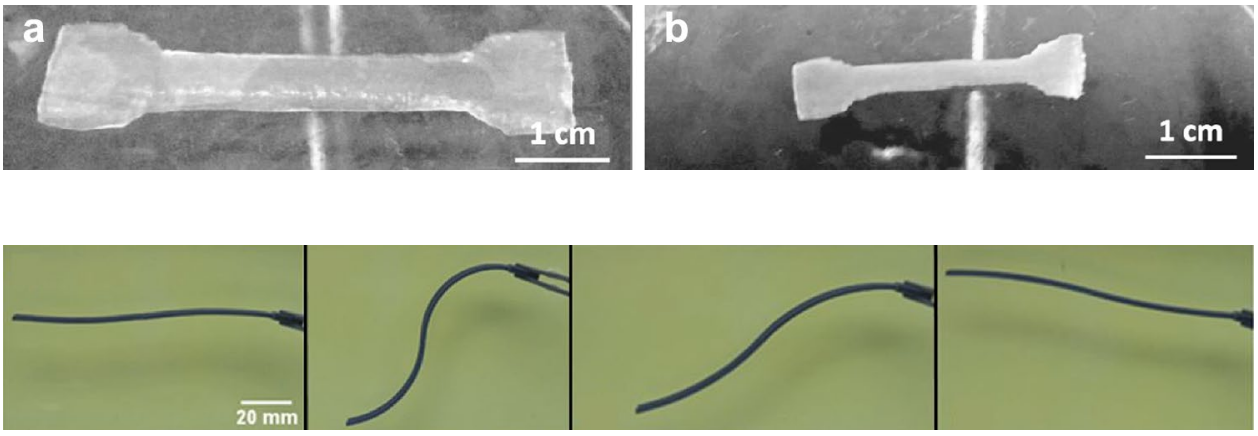
Fig. 19 The difference between waving and curling

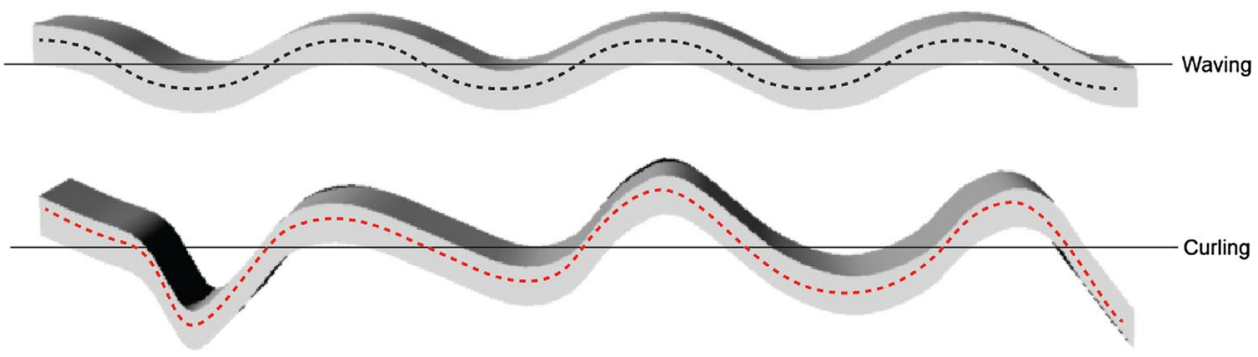

Fig. 20 An example of a curling behavior [52]
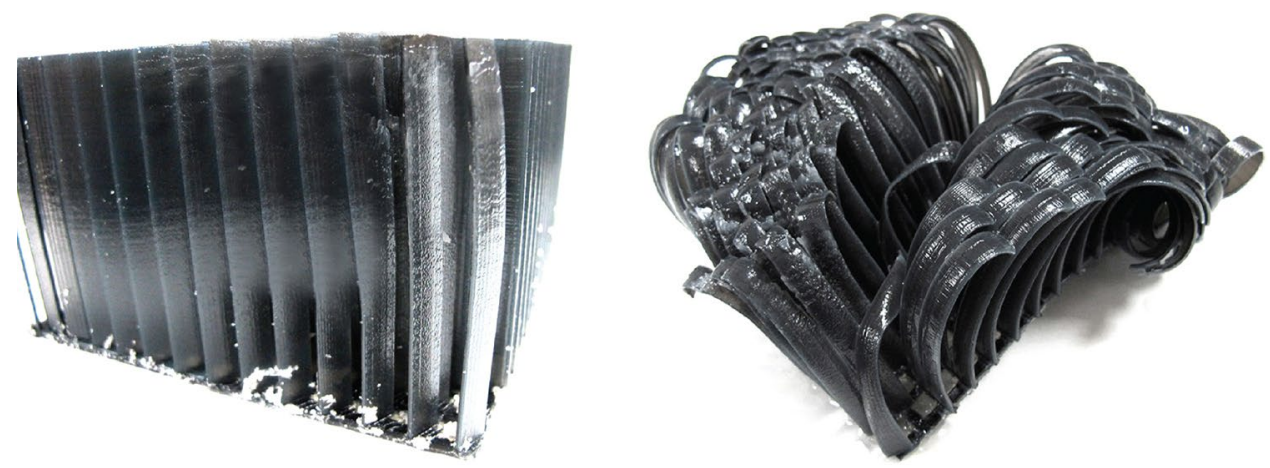

Fig. 21 An example of a multiple folding behavior [33]

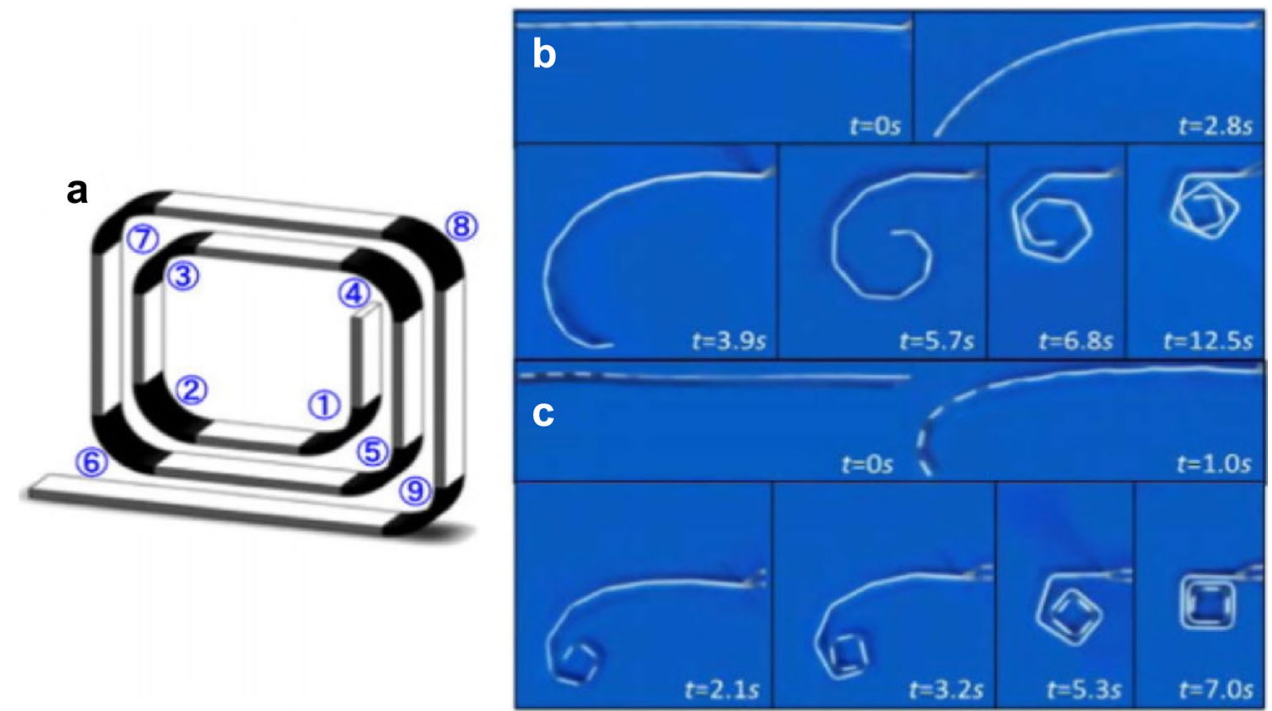

and recovery steps. Multiple folding behaviors can also be programmed in which the behavioral effects can be precisely timed to occur simultaneous or they can happen in a sequence. Even more complex folding has been demonstrated by Tibbits [51] where different material properties or geometric densities can be used to achieve this effect. The majority of the materials used in this study are digital materials being fabricated using AM machines such as the Objet Connex 260 from Stratasys. Digital materials are made by mixing the two basic model materials VeroWhite and Tangoblack before UV hardening. VeroWhite is a stiff plastic polymerized with ink-containing isobornyl acrylate, acrylic monomer, urethane acrylate, epoxy acrylate, acrylic monomer, acrylic oligomer, and photoinitiators at room temperature. TangoBlack is a rubbery material at room temperature polymerized by monomers. It is composed of urethane acrylate oligomer, exo-1,7,7trimethylbicyclo, hept-2-yl acrylate, methacrylate oligomer, polyurethane resin, and photo-initiators. The digital materials are composed of varying compositions of these two materials that lead to different thermo-mechanical properties [33]. 


\subsubsection{Multiple curving}

Tibbits [51] demonstrated a surface topographical alteration, as shown in Fig. 22. Three shapes evolved over a period of time, in which the generation of sinusoidal topographies (a continuous wave) is presented by the varying swelling ratios of rigid and active materials. Notably, the material concentration along the edges is different from the centre.

\subsection{Combination shape-changing behaviors}

Combination shape-changing behaviors consists of merging different types of shape-changing behaviors that result in an amalgamation of different deformation results to the component.

\subsubsection{Bending, twisting and waving}

Ge et al. [13] demonstrated the feasibility of combining twisting and bending; as well as bending and waving, as illustrated in Fig. 23. This shape-changing trait uses heat as stimuli in the typical shape-memory cycles with pre-defined programming and recovery steps.

\subsubsection{Expansion and contraction}

Manen et al. [30] demonstrated the combination of expansion and contraction, as illustrated in Fig. 24. They used a parallel arrangement of expansion and contraction strips to produce a mono-layer self-rolling element. In a separate experiment, arranging the strips at a $45^{\circ}$ angle in the longitudinal direction produced a self-twisting structure.

\subsubsection{Hierarchical structures}

Hierarchical structures combine various forms of shapechanging components into a system. Chen et al. [7] produced a single actuator $(\mathrm{a}, \mathrm{b})$ as a unit $(\mathrm{c}, \mathrm{d})$, following which the units were co-joined into a complete system $(e, f)$ and later into a much larger system of systems (g, h). (c, d) exhibits four actuators that are serially connected. Notably, the geometry of the bracket is the same as that of the pin. $(e, f)$

Fig. 22 An example of a multiple curving behavior [52]
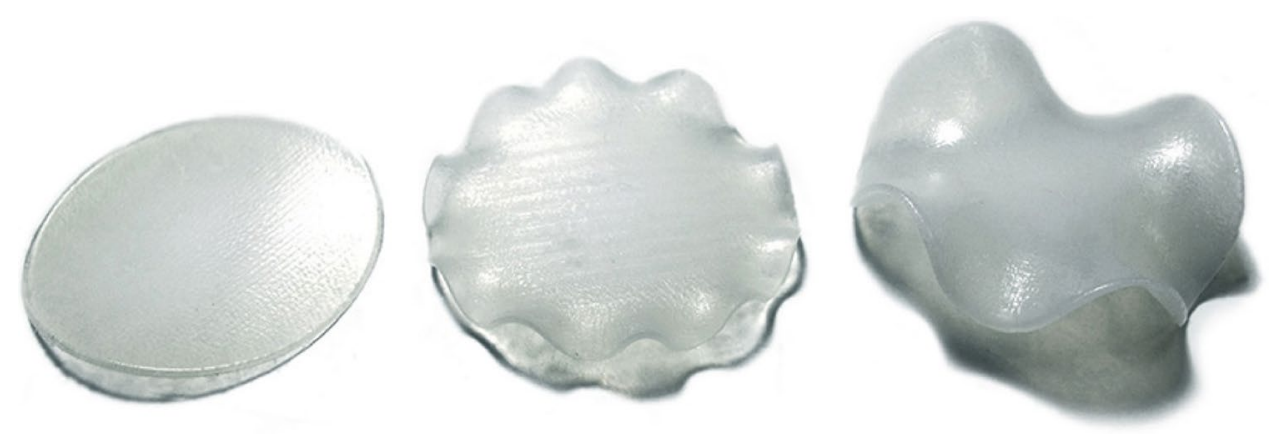

Fig. 23 An example of bending, twisting, and waving behavior [13]
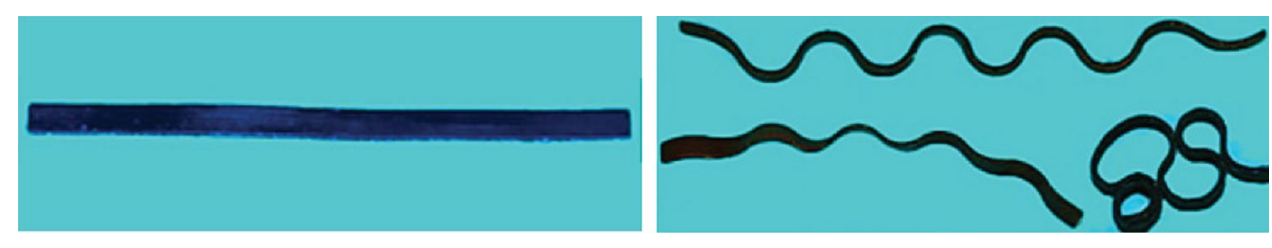

Fig. 24 An example of expansion, contraction, twisting, and bending behavior [30]

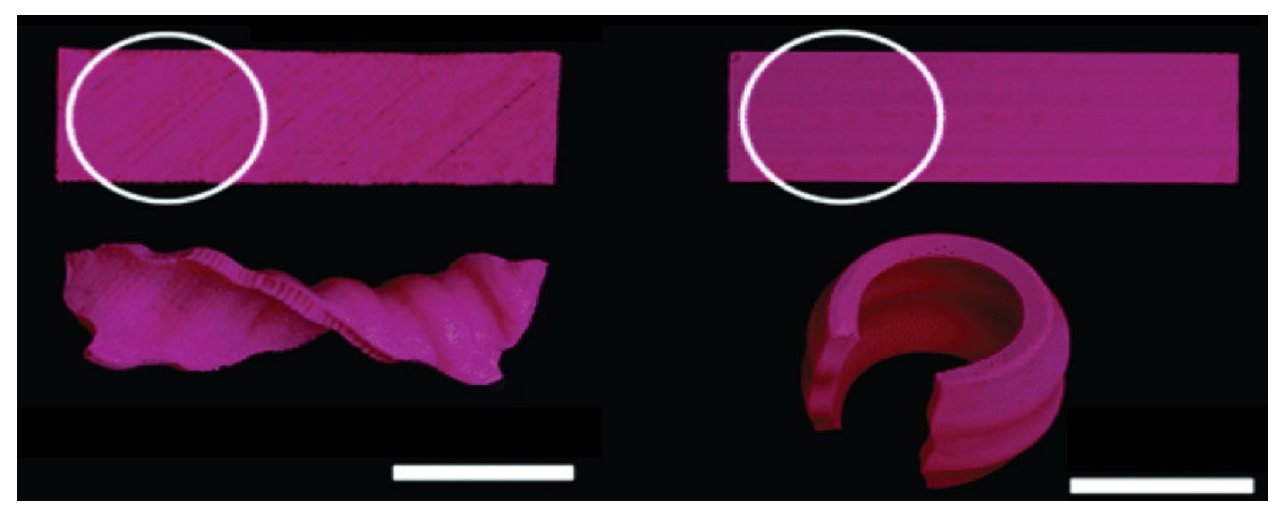


illustrates the tetrahedron module as well as global joints that are used to link the members. $(\mathrm{g}, \mathrm{h})$ exhibits the multiple tetrahedron units' tiling to showcase a space frame's deployment. All three corners of the top tetrahedron are linked to the top-most point of the three lower counterparts [7]. As a system, the entire assembly can be "programmed" to expand (or contract) in response to stimuli (Fig. 25).

\subsection{The need for a taxonomy}

As each author provides each different shape deformation with separate explanations and descriptions, it has become difficult to gain an overview of the types of shape-change behaviors that can be realized using 4D printing processes. Furthermore, the current knowledge in the literature is not only sparse, but also fragmented. The purpose of the taxonomy is an attempt to classify the different shape-change behaviors and to distinguish their corresponding characteristics. Understanding the types of shape-change behavior is essential for designers and engineers to implement suitable shape deformations within the CAD and programming process. To identify the types of shape-change behavior for $4 \mathrm{D}$ printed parts, we conducted a thorough review of the literature, and analyzed the types of shape deformations before summarizing this into a tabulated form. To develop the taxonomy, we first grouped all the types of shape deformation that were similar, paying a special attention to those types that were identical, but were named differently. The second step was to assign names to the taxons. In the process, we realized that all of shape-change behaviors are related in number of "sequential" shape-shifting process. Therefore, these shape-change behaviors were named "basic shape-change behaviors" and "complex shape-change behaviors." It can be mutually related and we assigned a new group known as a "Combination Shape-Change Behavior". We continued to proceed in this way to determine all the groups and categories.

\subsection{A taxonomy of shape-changing behaviors}

For the first category, we classify basic shape-changing as a single deformation that occurs from a single step or process. This includes folding, bending, rolling, twisting, helixing, buckling, curving, topographical change expansion, and contraction. The second category involves complex shapechanging behaviors in which the deformation can take place in either a single or multiple steps. Those that involve two more steps of deformation are also known as a "sequential" shape-shifting process whereby certain changes occurred at specific points of time. Complex shape-changing behaviors include multiple folding, multiple bending, multiple rolling, multiple twisting, multiple helixing multiple buckling, and multiple topographical and curvature changes are extensions of the basic form. Other even more complicated structures include waving and curling. The third category of shapechanging behaviors takes place in a combined form, whereby two or more constituent behaviors can be programmed to occur within the component. The classification table is illustrated in Fig. 26.

Taking a step further, we observe that basic shapechanging behaviors are often single-deformations, where the changes occur simultaneously. For more complex shapechanging behaviors, multiple deformations or "sequential" shape-shifting process can be programmed to occur. We
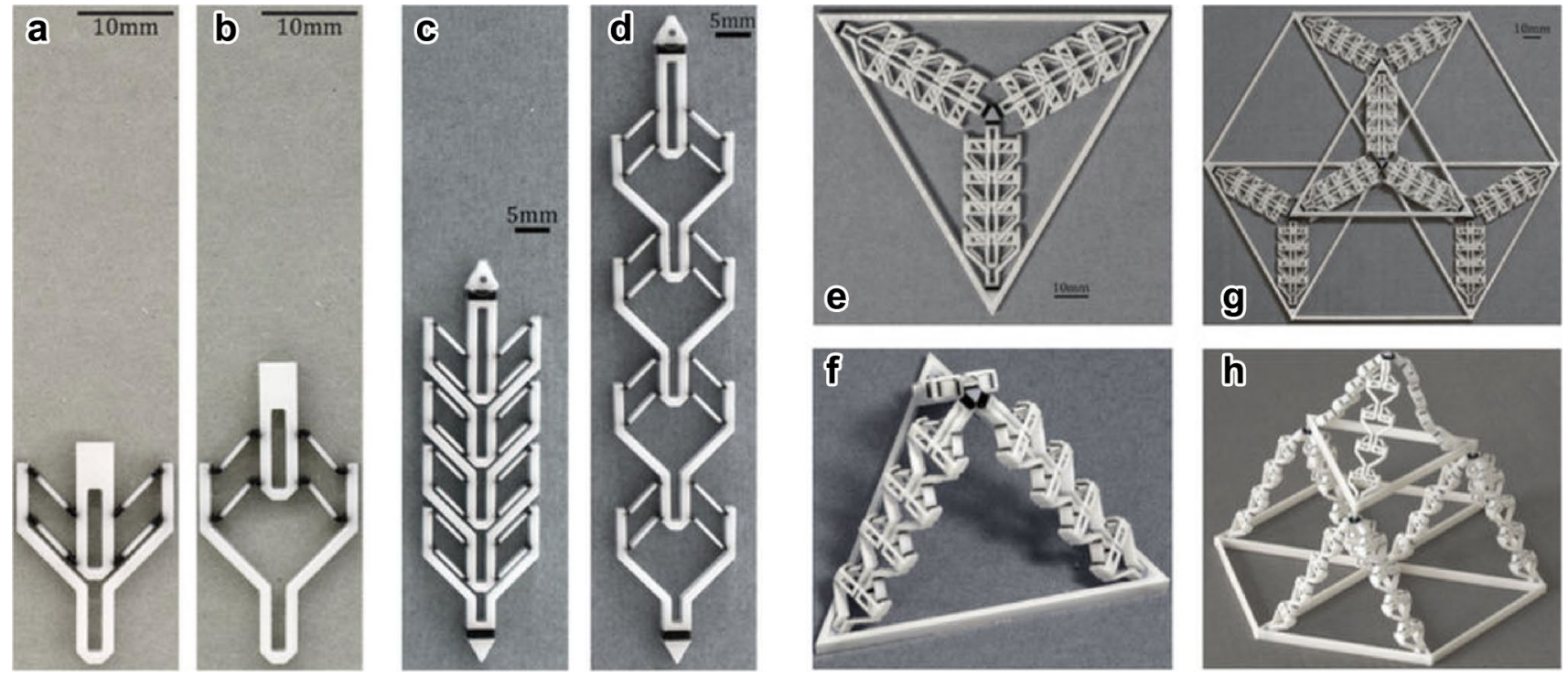

Fig. 25 An example of hierarchical structures [7] 
Fig. 26 A taxonomy of shapechanging behaviors of $4 \mathrm{D}$ printed parts

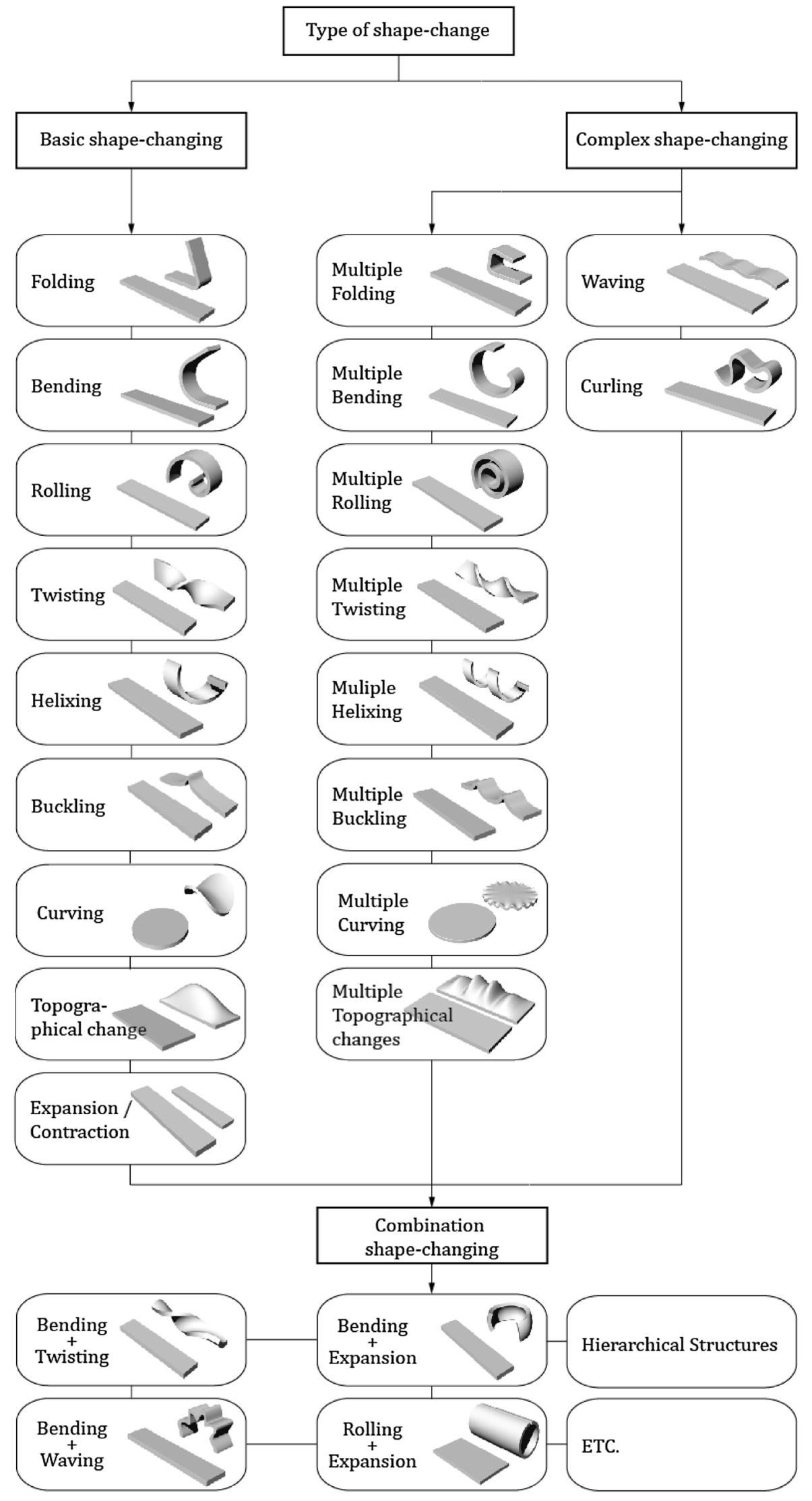




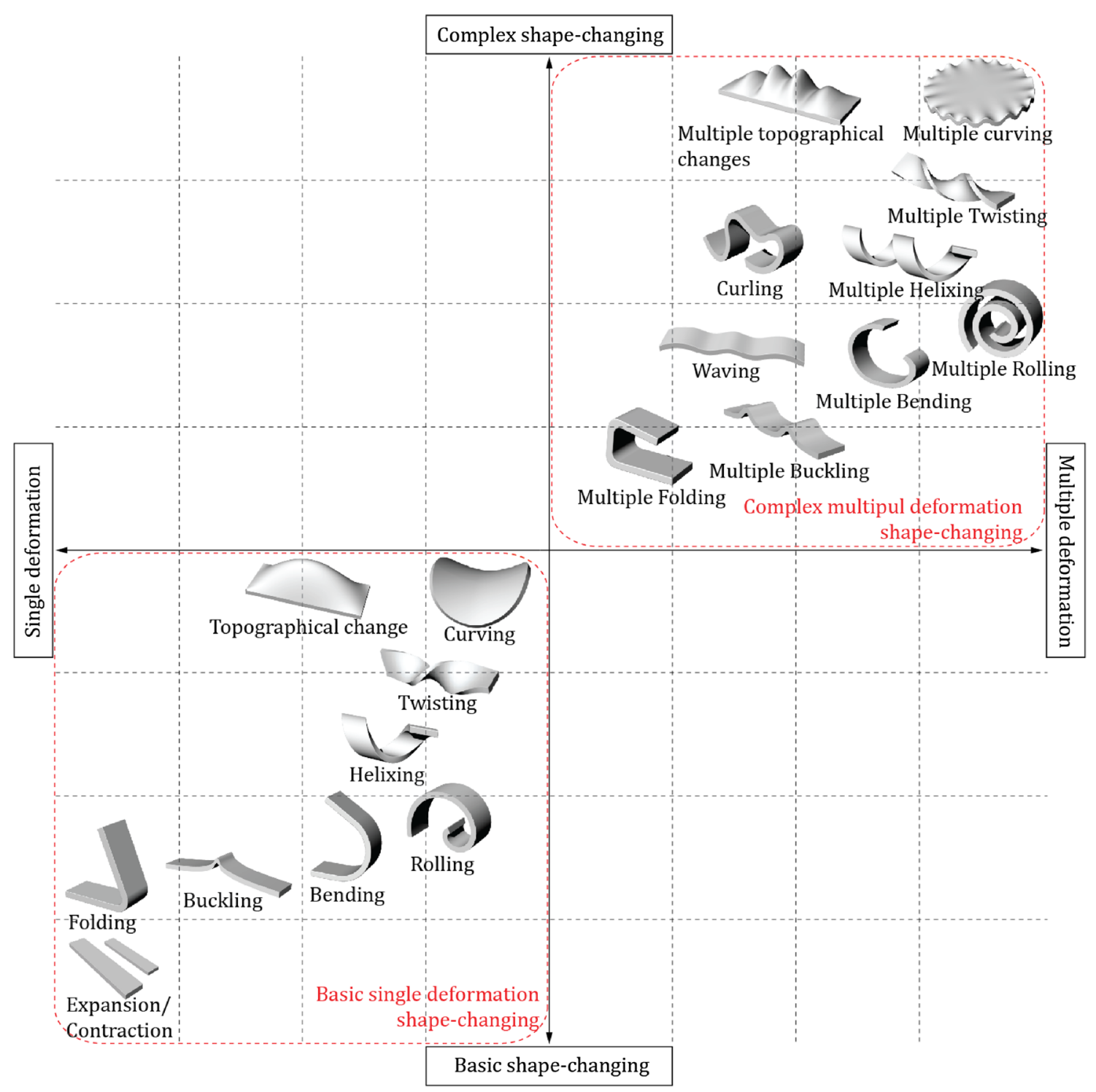

Fig. 27 Matrix of shape-changing behaviors and types of deformations in 4D printing

illustrate this phenomenon in Fig. 27, in which basic shape changes are limited to a single step of deformation and are located at the bottom corner of the matrix. Consequentially, complex shape changes that have the capability to have multiple deformation stages integrated into the design are located on the top right corner of the matrix.

\section{Summary}

$4 \mathrm{D}$ printing is increasingly gaining traction as a new technology that can overcome some AM limitations and yet also offering new applications. We view the essential elements of 4DP to include the AM process, the stimuli, the stimuli-responsive material, the interaction mechanism, and mathematical modeling. Against this backdrop, the paper provides an overview of shape-memoryshape-memory polymers (SMPs) and the various shape-changing behaviors. Designing features within the 4DP components allows simple structures to be manufactured before being activated into complex functional parts and structures. Upon activation, the 4DP components can be fixed or return into its original shape. One of the most important factors within the field of 4D printing is to understand the shape-change effect, which is dependent on three main factors based on the stimuli, the type of active material, and the computer-aided design. Therefore, it is important to specify the location of the shape change, understand the different types of shape-changing behavior, and how it behaves across time. Figure 28 presents this conceptual understanding that 4DP constitutes the AM process, the stimulus, 


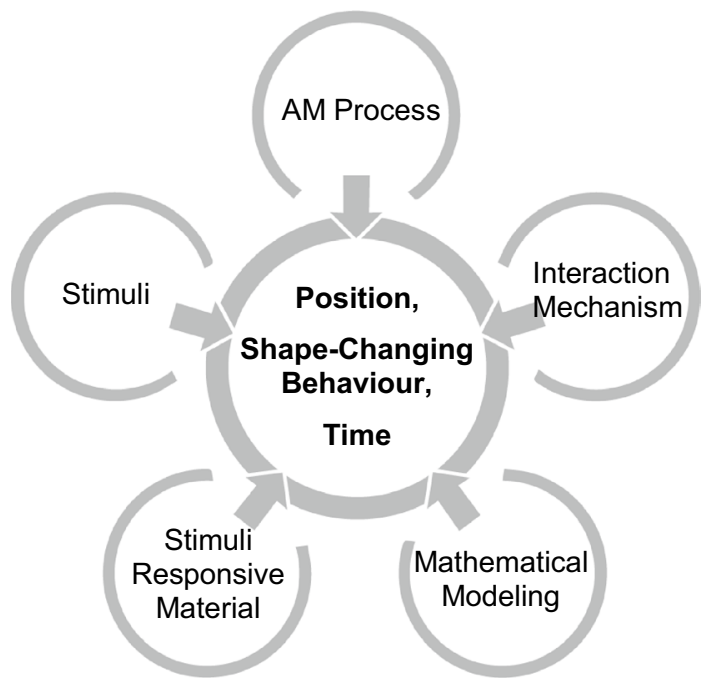

Fig. 28 A conceptual framework of 4D printing

stimuli-responsive material, interaction mechanism, and mathematical modeling; following which the 4DP effects itself are centered on the location, the shape-changing behavior, and also the behavioral change across time. Very little work has been carried out to cover these studies of transformational shapes and structures that can be achieved from 4D printing and design modeling of CAD in the programming $4 \mathrm{D}$ printed parts. However, it needs to apply which various methods of shape change are effectively for intelligent design modeling of $\mathrm{CAD}$, such as applying various printing shape changing. In the programming stage, designers and engineers need to understand and implement strategies using shape-change behavior to control the shape-change effect of 4D printed parts. This study can bridge the gap in the existing knowledge in this area. A key direction for future work would be to subject this taxonomy to a more thorough empirical survey and experiments for enhanced validation. Moreover, it will investigate the effect of relationship CAD programming and the shape change using SMPs through applying applications directly. It will analyze design direction which can predict the effect of shape change though appropriate CAD design.

Open Access This article is distributed under the terms of the Creative Commons Attribution 4.0 International License (http://creativeco mmons.org/licenses/by/4.0/), which permits unrestricted use, distribution, and reproduction in any medium, provided you give appropriate credit to the original author(s) and the source, provide a link to the Creative Commons license, and indicate if changes were made.

\section{References}

1. Armon S, Aharoni H, Moshea M, Sharon E (2014) Shape selection in chiral ribbons: from seed pods to supramolecular assemblies. Soft Matter 10:2733-2740
2. Balk M, Behl M, Wischke C, Zotzmann J, Lendlein A (2016) Recent advances in de-gradable lactide-based shape-memory polymers. Adv Drug Deliv Rev 107:136-152

3. Bakarich S, Gorkin R III, Panhuis M, Spinks G (2015) 3D/4D printing hydrogel composites: a pathway to functional devices. MRS Adv 1(8):521-526

4. Byun M, Santangelo C, Hayward R (2013) Swelling-driven rolling and anisotropic expansion of striped gel sheets. Soft Matter 9:8264-8273

5. Campbell T, Tibbits S, Garrett B (2014) The next wave: 4D printing programming the material world. Atlantic Council, Washington, D.C.

6. Cendula P, Kiravittaya S, Mei Y, Deneke C, Schmidt O (2009) Bending and wrinkling as competing relaxation pathways for strained free-hanging films. Phys Rev B 79:085429

7. Chen T, Mueller J, Shea K (2017) Integrated design and simulation of tunable, multi-state structures fabricated monolithically with multi-material 3D printing. Sci Rep 7:45671

8. Demaine ED (2001) Folding and unfolding linkages, paper, and polyhedra. Discrete and computational geometry. Springer, Berlin, pp 113-124

9. Erkeçoğlu S, Sezer AD, Bucak S (2016) Smart delivery systems with shape memory and self-folding polymers. In: Sezer AD (ed) Smart drug delivery system. ISBN 978-953-51-2247-0. https://doi.org/10.5772/62199

10. Farhang M, Seyed M, Xun L, Jun N (2017) A review of 4D printing. Mater Des 112:42-79

11. Forterre Y, Dumais J (2011) Generating Helices in Nature. Science 333:1715-1716. https://doi.org/10.1126/science.1210734

12. Frost and Sullivan (2014) Advances in 4D printing — next paradigm in manufacturing report D545-TI

13. Ge Q, Qi HJ, Dunn ML (2013) Active materials by four-dimension printing. Appl Phys Lett 103:131901

14. Ge Q, Dunn C, Qi H, Dunn M (2014) Active origami by 4D printing. Smart Mater 23:094007

15. Gladman AS, Matsumoto EA, Nuzzo RG, Mahadevan L, Lewis JA (2016) Biomimetic 4D printing. Nat Mater 15(4):413-418

16. Hornat CC, Yang Y, Urban MW (2017) Quantitative predictions of shape-memory effects in polymers. Adv Mater 29(7):1603334

17. Hu G, Damanpack A, Bodaghi M, Liao W (2017) Increasing dimension of structures by $4 \mathrm{D}$ printing shape-memory polymers via fused deposition modeling. Smart Mater 26:125023

18. Huang WM, Ding Z, Wang CC, Wei J, Zhao Y, Purnawali H (2010) Shape memory materials. Mater Today 13(7-8):54-61

19. International Standard ISO/ASTM52900 (2015) Additive manufacturing-general principles-terminology

20. Ionov L (2013) 3D microfabrication using stimuli-responsive self-folding polymer films. Polym Rev 53:92-107

21. Janbaz S, Hedayati R, Zadpoor AA (2016) Programming the shape-shifting of at soft matter: from self-rolling/self-twisting materials to self-folding origami. Mater Horiz 3:536-547

22. Khoo Z, Teoh J, Liu Y, Chua C, Yang S, An J, Leong K, Yeong W (2015) 3D printing of smart materials: a review on recent progresses in 4D printing. Virtual Phys Prototyp 10(3):103-122

23. Kim J, Hanna J, Hayward R, Santangelo C (2012) Thermally responsive rolling of thin gel strips with discrete variations in swelling. Soft Matter 8:2375-2381

24. Lauff C, Simpson T, Frecker M, Ounaies Z, Ahmed S, Lockette P, Strzelec R, Sheridan R, Lien J (2014) Differentiating bending from folding in origami engineering using active materials ASME. In: American Society of Mechanical Engineers, 2014, pp V05BT08A040-V005BT008A040

25. Lee A, An J, Chua C (2017) Two-way 4D printing: a review on the reversibility of 3d-printed shape memory materials. ScienceDirect 3(5):663-674 
26. Leng JS, Lan X, Liu YJ, Du SY (2011) Shape-memory polymers and their composites: stimuli methods and applications. Prog Mater Sci 56(7):1077-1135

27. Liu C, Qin H, Mather PT (2007) Review of progress in shapememory polymers. J Mater Chem 16:1543-1558

28. Liu Y, Genzer J, Dickey MD (2016) “2D or not 2D”: shape-programming polymer sheets. Prog Polym Sci 52:79-106

29. Lu H, Huang W, Yao Y (2013) Review of chemo responsive shape change/memory polymers. Pigm Resin Technol 42(4):237-246

30. Manen T, Janbaz S, Zadpoor A (2017) Programming 2D/3D shape-shifting with hobbyist 3D printers. Mater Horiz 4(6):935-1202

31. Manen T, Janbaz S, Zadpoor A (2018) Programming the shapeshifting of flat soft matter. Mater Today 21(2):144-163

32. Mao Y, Ding Z, Yuan C, Ai S, Isakov M, Wu J et al (2016) 3D printed reversible shape changing components with stimuli responsive materials. Sci Rep 6:24761

33. Mark C (2014) " $4 \mathrm{D}$ " printing: the next level of additive manufacturing. http://www.asme.org/engineering-topics/articles/manuf acturing-processing/4d-printing-next-level-additive-manufactur ing. Accessed 25 Feb 2018

34. Market Research Future (2018) 4D printing market research report-global forecast 2022. Market Research Future, Pune

35. Meng H, Li G (2013) A review of stimuli-responsive shape memory polymer composites. Polymer 54:2199-2221

36. Na J, Evans A, Bae J, Chiappelli M, Santangelo C, Lang R, Hull T, Hayward R (2015) Programming reversibly self-folding origami with micropatterned photo-crosslinkable polymer trilayers. Mater 27:79-85

37. Nkomo $N$ (2018) A review of 4D printing technology and future trends. SACAM 2018

38. N-Tech Research (2016) Future opportunities for metamaterials in aerospace and defense markets

39. Peltola S, Melchels F, Grijpma D, Kellomäki M (2008) A review of rapid prototyping techniques for tissue engineering purposes. Ann Med 40:268-280

40. Pei E (2014) 4D printing: dawn of an emerging technology cycle. Assembly Autom 34(4):310-314

41. Ratna D, Karger-Kocsis J (2008) Recent advances in shapememory polymers and composites: a review. J Mater Sci 43(1):254-269

42. Raviv D, Zhao W, McKnelly C, Papadopoulou A, Kadambi A, Shi B, Hirsch S, Dikovsky D, Zyracki M, Olguin C (2014) Active printed materials for complex self-evolving deformations. Sci Rep 18(4):7422

43. Roos Y, Karel M (1991) Plasticizing effect of water on thermal behavior and crystallization of amorphous food models. J Food Sci 56(1):38-43

44. Ryu J, D’Amato M, Cui X, Long KN, Qi HJ, Dunn ML (2012) Photo-origami-bending and folding polymers with light. Appl Phys Lett 100:161908
45. Satyanarayana P, Rani K, Lakshmi P, Krishna M (2018) Linear buckling analysis of atlas torpedo. IRJET 05(12)

46. Sharon E, Efrati E (2010) The mechanics of non-Euclidean plates. Soft Matter 6:5693-5704

47. Sun L, Huang W, Ding Z, Zhao Y, Wang C, Purnawali H, Tang C (2012) Stimulus- responsive shape memory materials: a review. Mater Des 33:577-640

48. Teoh JEM, Chua CK, Liu Y, An J (2017) 4D printing of customised smart sunshade: A conceptual study. In: da Silva FM, Bártolo H, Bártolo P, Almendra R, Roseta F, Almeida HA et al (eds) Challenges for technology innovation: an agenda for the future. CRC Press, London, pp 105-108

49. Thérien-Aubin H, Moshe M, Sharon E, Kumacheva E (2015) Shape transformations of soft matter governed by bi-axial stresses. Soft Matter 11:4600-4605

50. Tolley $M$ et al (2014) Self-folding origami: shape memory composites activated by uniform heating. Smart Mater Struct 23:094006

51. Tibbits S (2014) 4D printing: multi-material shape change. Archit Des 84(1):116-121

52. Tibbits S, McKnelly C, Olguin C, Dikovsky D, Hirsch S (2014) 4D printing and universal transformation. In: Proceedings of the 34th Annual Conference of the Association for Computer Aided Design in Architecture, pp 539-548

53. Wang W, Yao L, Zhang T, Cheng C, Levine D, Ishii H (2017) Transformative appetite: shape-changing food transforms from $2 \mathrm{D}$ to $3 \mathrm{D}$ by water interaction through cooking. In: ACM 978-1-4503-4655-9/417/05

54. Wu J, Yuan C, Ding Z, Isakov M, Mao Y, Wang T, Dunn M, Qi $\mathrm{H}$ (2016) Multi-shape active composites by 3D printing of digital shape-memory polymers. Sci. Rep 6:24224

55. Wu M, Xue H, Pei T (2013) A novel construction method of low/ no-hit zone frequency hopping sequence set based on interleaving technique. Nat Commun 4:1586

56. Yu K, Dunn ML, Qi HJ (2015) Digital manufacture of shape changing components. Extreme Mech Lett 4:9-17

57. Zhang Q, Zhang K, Hu G (2016) Smart three-dimensional lightweight structure triggered from a thin composite sheet via $3 \mathrm{D}$ printing technique. Sci Rep 6:22431

58. Zhao Z, Wu J, Mu X, Chen H, Qi J, Fang D (2017) Origami by frontal photopolymerization. Science 3(4):e1602326. https://doi org/10.1126/sciadv.1602326

Publisher's Note Springer Nature remains neutral with regard to jurisdictional claims in published maps and institutional affiliations. 